\title{
Study on the Architecture of China's Innovation Network of Automotive Industrial Cluster
}

\author{
Min Zhang ${ }^{1}$ \\ ${ }^{1}$ School of Economics and Science, Chang Chun University of Science and Technology, Chang Chun, China \\ Correspondence: Min Zhang, School of Economics and Science, Chang Chun University of Science and \\ Technology, The first building 403room, Satellite road 7989, Chang Chun, China. Tel: 86-139-0431-0731. \\ E-mail: zmzs10118@163.com
}

Received: September 15, 2014

Accepted: October 23, 2014 Online Published: October 26, 2014

doi:10.5539/emr.v3n2p69

URL: http://dx.doi.org/10.5539/emr.v3n2p69

\begin{abstract}
In today's world, as a popular and highly efficient means of transportation, automotive has become an important symbol of modern society. Automotive industry is regarded as the "core industry" and is an important manufacturing industry. It has high degree of industrial correlation and significant benefits of scale economy. The industry is capital and technology-intensive. The development of automotive industry itself cannot only bring direct economic benefits but also is an essential prerequisite for the development of a modern economy. Since the reform and opening up, the production scale of China's automotive industry has been expanding continuously. China has formed a relatively complete industrial production base and a sound product system, which occupy an important position in national economy. FAW Group, SAIC MOTOR, Dongfeng Motor Corporation and other domestic backbone automotive enterprise groups have a very strong accumulation in capital, technology, personnel, network, brand reputation, etc. The overall technological innovation capability of the automotive industry cluster is improving and the innovation network has already come into being.
\end{abstract}

Keywords: automobile industry cluster; innovation network

\section{The Architecture of Innovation Network of China's Automotive Industry Cluster}

In recent years, due to increasingly fierce international competition and national attention given to technological innovation, the prototype of innovation network of China's automotive industry cluster has emerged. For example, FAW Group has gradually formed a network with Changchun as the center and Qingdao, Wuxi and Tianjin as the auxiliary areas. A number of small and medium size enterprises (SMEs) are gathered together to form an innovation network that is market-oriented and combines learning, scientific research and production. The technological innovation institutions of the network form a technology alliance and carry out cooperation in production and scientific research. The innovation network of China's automotive industry cluster can be divided into core network, secondary network and peripheral supporting network. They are interconnected through formal and informal exchanges.

According to Hakansson's (1987) point of view, any network consists of three basic variables: actors, resources and occurrence of activities. This study also adopts this point of view to analyze the structure of innovation network of China's automotive industry cluster using the three basic variables(Gupta, 1991) .

According to the innovation features of China's automotive industry cluster, this study divides the actors of the cluster into enterprises in automotive industry, users of industrial chain, universities and research institutions, government, financial institutions, and agencies, which will be analyzed separately.

\subsection{Enterprises in Automotive Industry}

China's automotive industry cluster is composed of a number of enterprises which are identical or similar in production and operation mode. Therefore, the enterprises are the most important innovation actors in automotive industry. They have the function of investing in technological innovation, conducting research and development, and commercializing the innovative technologies. Whatever the form of industry cluster is, the ultimate value of its innovation must be achieved through enterprises. Therefore, in the economic sense, any innovative automotive cluster enterprise can be the actor. Technological innovation does not require the enterprises to undertake the entire process of research and development, or pilot-scale test and production. 
Instead, they can use the resources of other enterprises by means of open technology transfer and cooperation to achieve innovation in product or process, improvement in organization and management, and expansion of market and profits. In China's automotive industry cluster, innovation is mainly achieved through the strategic behaviors of enterprises. On one hand, the enterprise compete with each other through technological innovation and other innovations; on the other hand, they also cooperate with other enterprises through strategic alliance to achieve integration and development of the resources, which finally improves the innovative capability of the entire automotive industry cluster.

\subsection{Users of Industrial Chain}

The concept of "user-centered design" was first proposed by Donald Norman from the institute of the University of California in San Diego. After improvement by many experts, it has become the most influential design philosophy since the 1980s (also known as design methodology), which can be implemented through a variety of ways. For example, ergonomics, human factor engineering, universal design, empathic design, emotional design, user research, etc (Cooper, 1983). In China's automotive industry, user needs is a basic starting point for innovative activities. It is also an important source of driving force for innovation. It can be said that all innovative activities are designed to meet the user needs. If there is no market demand, any innovation will be unprofitable. This makes clear the direction for the automotive industry in conducting innovative activities.

\subsection{Universities and Scientific Research Institutions}

Universities play a fundamental role in the innovative activities of China's automotive industry. They not only undertake the task of scientific research and development but also conduct trainings and knowledge dissemination. Most importantly, they continuously supply creative talent for the automotive industry, so as to promote the technological innovation of the entire automotive industry. Research institutions provide knowledge and technical support for technological innovation through the development of new products and technologies to promote technological innovation of the industry. For China's automotive industry, research institutions mainly focus on overcoming key technical difficulties to promote technological innovation of automotive industry from the aspect of supplying technical knowledge.

\subsection{Government}

Government is one of the main actors of China's automotive industry cluster innovation. Government acts as a guide and protector for automotive industrial innovation. It fulfills the function of developing policies, regulations, plans, implementing macro-control, and providing common technology and facilities. As the actors of automotive industrial innovation, local governments lay down the regulation on innovation system of China's automotive industry. They are also the participants of the innovative activities. Local governments develop plans to promote the development of automotive industry and design and establish various development mechanisms. They play an extremely important role in technological innovation, technology transfer, technological transformation and other activities in China's automotive industry. For automotive industrial innovation, government is not only the "visible hand" but also one of the most important direct protectors. Although governmental sectors are not the direct participants of innovative activities, they play an irreplaceable role in the creation of an innovative environment for cluster: promoting formation and development of innovation networks, effectively regulating the behaviors of the local market, and preventing market failure and system failure in the process of innovation. Therefore, government acts as a bridge between the network and actor. It actively creates an "innovative environment", making knowledge and information diffusion more accurate and effective and innovation process smoother.

\subsection{Financial Institutions}

Previous experiences show that sound capital market and financial environment are the foundation and guarantee for vigorous scientific and technological development. They can substantially increase the scientific and technological innovation capability of the industry. Therefore, financial institutions play an important role in innovative activities of China's automotive industry and are one of the main sources of funding for the latter. It provides strong support for commercialization, industrialization and internationalization of the high-tech of China's automotive industry (Tidd, 2001).

For a long time, China has been attaching great importance to supporting technological innovation. Financial institutions play a pivotal role in China's automotive industrial innovation. Financial institutions not only provide an important source of funding for technological innovation of automotive industry, but also support the commercialization, industrialization and internationalization of high-tech. Modern economy is the economy having finance as one of the leading factors and combing virtual economy with real economy. As a new 
paradigm of economic development, technological innovation will be more dependent on good financial support. For example, Wuhan Branch of Huaxia Bank has provided financial services for supply chain of Dongfeng Honda, Dongfeng Citroen, Dongfeng commercial vehicles, Dongfeng light truck (pickup), Dongfeng Nissan, FAW Toyota, Huangzhou Honda, Huangzhou Toyota, and other mainstream brand cars. In 2009, a total of over 13 billion was invested in the supply chain for more than 120 raw materials and automotive parts suppliers, car manufacturers, and auto dealers.

\subsection{Intermediate Organization}

Intermediate organization is the professional body intermediate between the enterprises in China's automotive industry and related organizations. It is engaged in communication, coordination, consultation and other service activities to enhance the competitiveness of the manufacturing industry, without taking part in production and operation activities. When China's automotive industry had reached a certain scale, the emergence of industry agencies is inevitable, such as industrial association, innovation center, scientific and technological development center, information service center, network center, and training institutions. Intermediate organization is the lubricant that ensures smooth functioning of the market economy and is the supporting system for normal operation of the industry. Its main function is to provide intermediary services for both parties to reduce transaction costs, especially the information cost, therefore facilitating the knowledge flow of the industry. Intermediate organizations play the "gluing" and supporting role for the collaborative innovation. Intermediate organization is the link between production, learning and scientific research by various actors and creates connections with a variety of innovation resources and actors to achieve collaborative innovation at low transaction costs and risks. Because it gathers experts from the fields of information, technology, investment, and management together, it can provide specialized services for enterprises. It helps them gain market opportunities and investment, effectively reduce the competition risk in early business growth, facilitate the scientific inventions to enter into relevant economic fields quickly, and accelerate commercialization of the technological achievements.

\section{Hierarchy of Innovation Network of China's Automotive Industry Cluster}

Innovation network of the cluster is significantly hierarchical. Innovation network is composed of two levels of actors as well as the interactions between them. The first type of actors are the enterprises in industrial cluster and the supporting industry; the second type of actors are the institutional infrastructure, including universities, research institutions, financial institutions and immediate organization; the third type of actors are mainly governmental sectors, which create advantageous innovation environment, provides infrastructures and institutional improvement, and makes favorable policies to facilitate the economic development in the cluster. At the same time, they establish direct or indirect relationships with various network nodes in the cluster, including enterprises, universities, research institutions, financial institutions, etc. Generally, the relationship between governmental sectors and enterprises and other network nodes is mainly indirect in developed countries; while in developing countries, such as China, governmental sectors play a greater role in the cluster network. Government has a very close connection with other network nodes, especially enterprises. In addition to policy-making, government is also directly involved in enterprises' innovative activities (SUN Bing, 2008).

A significant external feature of innovation network of China's automotive industry cluster is the geographic agglomeration of a large number of similar or related enterprises. For example, FAW Group has gradually formed a network with Changchun as the center and Qingdao, Wuxi and Tianjin as the auxiliary areas. The innovation network is market-oriented, and combines production and learning with scientific research. Therefore, the hierarchy of innovation network of China's automotive industry cluster is first manifested as the interactive network established between enterprises in the cluster through formal and informal contacts and exchanges.

According to the coupling elements at different levels, the innovation network of China's automotive industry cluster can be divided into three levels: core network, secondary network, and peripheral supporting network. They are interconnected through formal and informal exchanges. The purpose of the network is to develop the collaborative capacity to solve the problems occurring in technological innovation. Through such a systematic construction, the enterprises in the innovation network of China's automotive industry cluster will achieve important cross-breeding of synergies and technology products and enhance competitiveness and innovation to promote the development of innovation network of China's automotive industry.

Based on the analysis above, this study divides the macro architecture of innovation network of China's automotive industry cluster into three levels. 


\section{1) Core network}

It is composed of the interaction between the core enterprises in the innovation network of China's automotive industry and related enterprises. Through collaborative development with upstream suppliers, enterprises can get the latest materials and production techniques and maintain competitive advantages in product quality and production processes. Through information interaction with downstream customers and distributors, they can acquire the latest market information to adjust research and development, production and sales. The small and medium-sized enterprises (SMEs) in China's automotive industry cluster produce and conduct innovative activities centering around large core enterprises. Information exchange and sharing between large core enterprises and SMEs are an important means for China's automotive industry to stimulate innovation and diffusion of innovations.

\section{2) Secondary network}

Government, universities, research institutions, intermediate organization, and financial institutions constitute the supporting network. The role of the supporting network is fulfilled through connections with the core network. Universities and research institutions are specialized agencies in knowledge creation and dissemination. They not only provide the latest knowledge and technology for enterprises in innovation network of China's automotive industry, but also supply creative talents for the enterprises. Meanwhile, they help increase the number of entrepreneurial and innovative enterprises in the network and support explicit knowledge stocks and flows in the entire automotive industry cluster. Intermediate organization, especially trade associations and consulting firms can regulate cooperation and competition between the enterprises in the innovation network of China's automotive industry cluster and promote knowledge integration and innovation diffusion in the cluster. Financial institutions can provide financial support for high-risk and high-yield innovation and research and development activities of the automotive enterprises.

3) Policy and socio-cultural level

It refers to the policies and regulations, cultural traits, habits and norms and other intangible resources of the area where China's automotive industry cluster is located. The classical network theory emphasizes that network is a system composed of nodes and links, which obviously does not apply to social and cultural networks. However, from the perspective of embeddedness, actors always act within a certain network. They are not only subject to the network where they are located, but are also affected subtly by social structure. As the structural characteristics of regional community, culture has a profound impact on the innovation behavior and efficiency of the enterprises in automotive industry cluster. In some clusters with innovative and collaborative cultural tradition, high degree of trust and cooperation between the network actors will promote exchange and interaction between the enterprises in the cluster and between the enterprises and intermediate organization. It also stimulates high-speed flow and sharing of information and knowledge in the network, which improves the innovation ability of the entire industrial cluster.

\section{Conclusion}

This article introduces the basic theory and structure of innovation network of China's automotive industry. We first establish the architecture of innovation network of China's automotive industry cluster and explore the roles of actors and hierarchies. The actors of the innovation network mainly include the enterprises, users of industrial chain, universities and research institutions, government, financial institutions and intermediate organizations in the automotive industry. It also divides innovation system of China's automotive industry cluster into three levels: core level, secondary level and policy and socio-cultural level.

\section{Acknowledgements}

This work was financially supported by the youth fund of Chang Chun University of Science and Technology (XQNJJ-2011-14). I thank the sustentation fund for this article.

\section{References}

Gupta, A. K. R. (1991). Everett M. Internal Marketing: Iniegrating $R \& D$ and Marketing within the Organization. England, W Yorkshire: Journal of Services Marketing.

Cooper, R. G. (1983). The Impact of New Product Strategies. DC: Industrial Marketing Management.

Tidd, J. (2001). Innovation management in context: Environment, organization and performance. USA: International Journal of Management Reviews.

Sun, B. (2008). Self-directed innovation dynamic system on the synergy theory explanation. China: Commercial economy and management. 


\section{Copyrights}

Copyright for this article is retained by the author(s), with first publication rights granted to the journal.

This is an open-access article distributed under the terms and conditions of the Creative Commons Attribution license (http://creativecommons.org/licenses/by/3.0/). 